\title{
Poststreptococcal syndrome mimicking conjunctival lymphoma
}

\author{
Iwona Rospond-Kubiak* , Agata Brązert ${ }^{1}$, Jarosław Kocięcki ${ }^{1}$ and Jan Bręborowicz ${ }^{2}$
}

\begin{abstract}
Background: Poststreptococcal syndrome (PSS) can be a consequence of nonpurulent primary infection with group A streptococci (GAS). Postreptococcal uveitis is a well recognized entity with quite a few descriptions in the literature, but so far no conjunctival involvement has been reported.

The aim of the study is to present a rare case of postreptococcal conjunctival lesions mimicking a lymphoma.

Case presentation: 19-years-old Caucasian female presented with pink, nodular infiltrates in the right conjunctiva that occurred a few months after upper respiratory tract infection and tonsillectomy. Histopathological examination of collected lesion samples revealed inflammatory reaction with lymphocytes proliferation and failed to rule out a myeloma. Complementary flow-cytometry did not show monoclonal proliferation of lymphocytes B. During followup we observed the complete regression of conjunctival lesions after the benzyl penicillin treatment prescribed by ENT specialist due to elevated plasma ASO levels. Therefore, we suppose that those lesions must have represented a part of poststreptococcal syndrome.
\end{abstract}

Conclusions: To conclude, this is, to the best of our knowledge, the first report of conjunctival involvement in the course of PSS related to group A streptococci.

Keywords: Postreptococcal syndrome, Anti-streptolysine 0, Conjunctival lymphoma

\section{Background}

Poststreptococcal syndrome (PSS) is a sterile inflammation thought to represent an autoimmune reaction between streptococcus-sensitized lymphocytes and host tissue because of 'molecular mimicry'. It can be a consequence of nonpurulent primary infection with group A streptococci (GAS). The most common forms of PSS are: rheumatic fever, acute poststreptococcal glomerulonephritis and erythema nodosum.

Ocular tissues involvement in PSS has been rarely reported in literature in the form of poststreptococcal uveitis secondary to group A streptococcal infection [1-5] and keratouveitis after a pharyngitis caused by group C streptococci (GCS) [6]; but, to date, conjunctival involvement has not been reported.

Poststreptococcal uveitis can affect any part of the uvea and is almost always bilateral, nongranulomatous with the occasional formation of posterior synechiae. It

\footnotetext{
* Correspondence: iwona.rospond-kubiak@wp.pl

'Department of Ophthalmology, Poznań University of Medical Sciences, 1/2 Długa St., Poznań 61-848, Poland

Full list of author information is available at the end of the article
}

appears to be a disease of young patients ( $96 \%$ under 40 years of age, and more than $50 \%$ younger than 15 years) [4]. There is a controversy regarding the recognition of PSS syndrome only after an elevated anti-streptococcal lysine $\mathrm{O}$ (ASO) titer, which may variate regarding the patient age, ethnicity and season of the year [3]. The streptozyme agglutination test (SAT) represent another diagnostic option.

The aim of the study is to present a rare case of postreptococcal conjunctival lesions mimicking a lymphoma.

\section{Case presentation}

A 19-year-old Caucasian female was referred to the Ocular Oncology Service, Department of Ophthalmology, Poznań, Poland in April 2009 with a suspicion of conjunctival lymphoma. The patient reported the appearance of painless reddish nodules on the right bulbar conjunctiva couple weeks previously. The patient didn't have past ocular history of note. Her past medical history revealed history of purulent tonsillitis treated with systemic antibiotic therapy a year earlier. However, after this treatment the levels of antistreptolysin (ASO) were

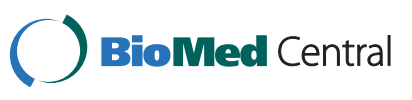


still elevated (up to $500 \mathrm{U} / \mathrm{ml}$ ) and the patient had undergone tonsillectomy three months later. The working clinical diagnosis by her local ophthalmologist was of suspected lymphoma and the patient received no topical treatment. At presentation to our department, the ASO level was $482 \mathrm{U} / \mathrm{ml}(\mathrm{N}: 10-200 \mathrm{U} / \mathrm{ml})$ and other laboratory test results were within normal limits. The patient was otherwise healthy with no travelling history and reported no coincidence between the appearance of conjunctival lesions and tonsillitis.

On ocular examination, the best corrected visual acuity was $5 / 5$ with the right eye and $5 / 5$ with the left eye, which was healthy. On biomicroscopy there were numerous, pink and reddish nodules on the right bulbar conjunctiva nasally and temporally [Figure $1 \mathrm{~A}$ and $\mathrm{B}$ ]. Those lesions seemed to be tightly fixed to the sclera. There was a similar subconjunctival mass in the right lower fornix. Otherwise the anterior segment appeared normal, with no signs of uveitis or keratitis. The right fundus appeared normal. Orbital ultrasound revealed no pathology. No lymphadenopathy was noted. Because the observed lesions did not have the typical appearance of a conjunctival lymphoma and the diagnostic uncertainty, incisional biopsy was taken.

The histopathological assessment of the collected specimens revealed infiltration by plasma cells and lymphocytes. The immunohistochemistry enabled recognition of B cells $(\mathrm{CD} 20+)$ and T cells $(\mathrm{CD} 3+)$, which showed enhanced expression of Ki-67. Expression of CD 10, CD 23, CD 43 and bcl2 was also detected [Figure 2]. This might have corresponded to an inflammatory process, but also to a conjunctival infiltration in the course of multiple myeloma. As a part of further management, a bone marrow biopsy was performed. Flow cytometry revealed $25.5 \%$ lymphocytes without evidence of monoclonality, $4 \%$ monocytes, $69.5 \%$ neutrophils and $1 \%$ mieloblasts. Other systemic investigations (chest $\mathrm{X}$-ray, abdomen ultrasound) revealed no pathology.

On the next follow-up visit, 2 months later, in June 2009, shrinking and pallor of the conjunctival lesions was noted. [Figure $1 \mathrm{C}$ and $\mathrm{D}$ ]. The patient reported receiving treatment with benzyl penicillin $(6 \times 2.4 \mathrm{mln}$ units every two weeks) 4 weeks earlier by the ENT specialist because of persistent elevation of the plasma concentration of ASO. At the next follow-up in 6 weeks time the conjunctival lesions had completely disappeared.

\section{Discussion}

In view of the clinical progress of our case, the likely diagnosis of poststreptococcal syndrome (PSS) affecting the conjunctiva that had responded to penicillin treatment was made. The differential diagnoses for that case would be anterior scleritis or episcleritis, conjunctival lymphoma, ocular infiltration in the course of multiple myeloma, reactive lymphoid hyperplasia, tuberculosis, chlamydia or herpetic infection, papilloma and superficial migratory phlyctenulosis.

The first two conditions could be ruled out since the lesions initially were painless. However, a multifocal nodular episcleritis and scleritis can sometimes appear in the course of Hodgkin's lymphoma but the onset of a disease in the cases reported in the literature was associated with pain [7]. Similarly, the clinical findings could have been part of myeloma [8]. Although histopathologic examination revealed an infiltration by plasma cells and lymphocytes, further hematologic and systemic

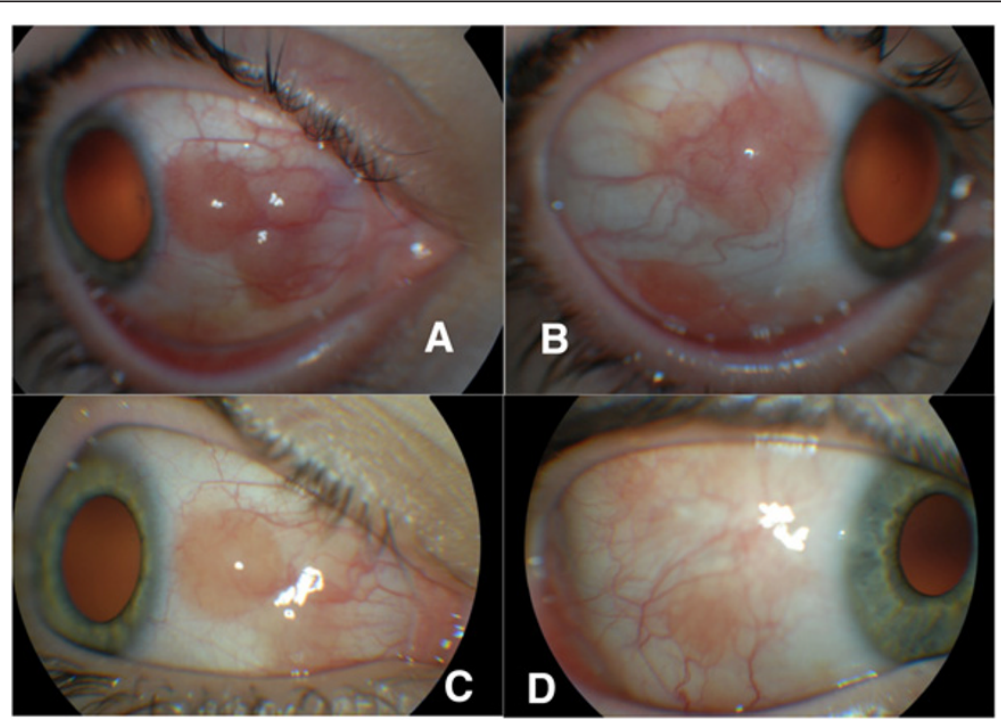

Figure 1 (A + B) - Anterior segment of right eye (RE) - April 2009, and disappearance of conjunctival lesions after benzyl penicilin treatment in June $2009(C+D)$. 


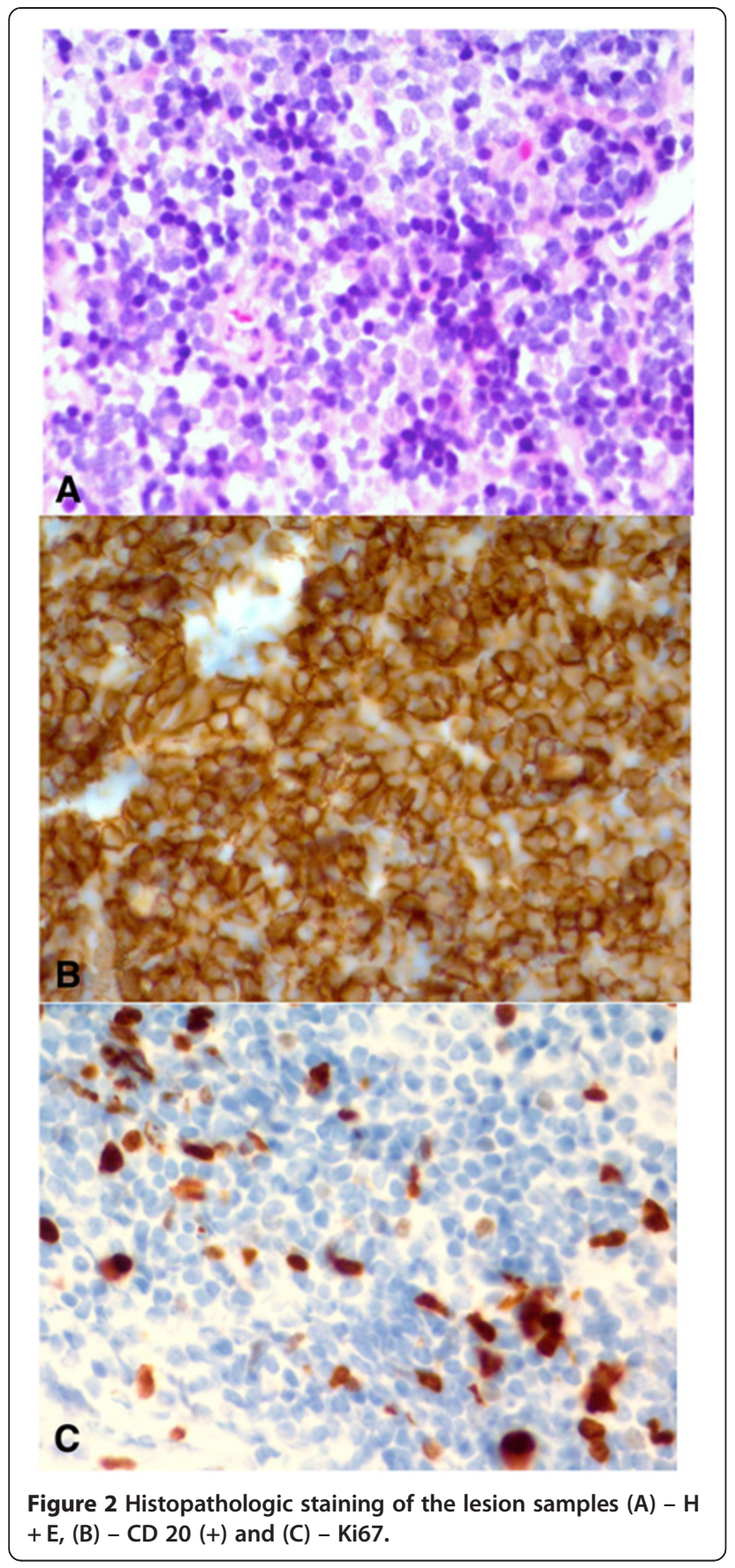

investigations (bone marrow biopsy and flow cytometry) ruled out multiple myeloma and other lymphoproliferative disease [9]. There was no discharge, no lymphadenopathy, no corneal involvement at first presentation and no systemic signs of infectious disease which let us to rule out tuberculosis, chlamydia or herpes infection although the collected lesion samples were not evaluated with PCR for a specific DNA.

Furthermore, we observed the diminution of all lesions after benzyl penicilin treatment due to elevated plasma concentration of ASO which seems to confirm the final diagnosis.

\section{Conclusion}

To conclude, this is, to the best of our knowledge, the first report of conjunctival involvement in the course of PSS related to group A streptococci.

\section{Consent}

Written informed consent was obtained from the patient for publication of this Case report and any accompanying images. A copy of the written consent is available for review by the Series Editor of this journal

\section{Competing interests}

The authors declare that they have no competing interests.

\section{Authors' contributions}

IRK performed the incisional biopsy, was responsible for the clinical management of the patient, prepared most of the manuscript; $A B$ collected the photograps and prepared a clinical part in the first draft of the manuscript, JK supervised the clinical management of the patient, made the literature search and set the final diagnosis, JB evaluated the histopathology. All authors revised and accepted the final version of the manuscript.

\section{Acknowledgments}

This work received no specific grant from any funding agency in the public, commercial or not-for-profit sectors.

\section{Author details}

'Department of Ophthalmology, Poznań University of Medical Sciences, 1/2 Długa St., Poznań 61-848, Poland. 'Department of Oncologic Pathology, Chair of Oncology, Poznań University of Medical Sciences, 1/ 2, Łąkowa St, Poznań 61-878, Poland.

Received: 27 May 2012 Accepted: 15 March 2013 Published: 25 March 2013

\section{References}

1. Hanno E, Gay D, Boyer S: Two differing presentations of chronic bilateral anterior uveitis. Optometry 2009, 80:70-75.

2. Viel A, Kolyvras N, Catherine J, et al: Post-streptococcal uveitis. J Fr Ophtalmol 2011, 34(4):256. e1-6.

3. Gallagher MJ, Mahiul MK, Muqit MMK, David Jones D, Gavin M: Post-streptococcal uveitis. Acta Ophthalmol Scand 2006, 84:424-428.

4. Rehman S, Anand S, Reddy A, et al: Poststreptococcal syndrome uveitis. Ophthalmol 2006, 113:701-706.

5. Holland GN: Recurrent anterior uveitis associated with streptococcal pharyngitis in a patient with history of postreptococcal syndrome. Am J Ophthalmol 1999, 127:346-347.

6. Nataneli N, Aguilera ZP, Rosenbaum PS, et al: Poststreptococcal keratouveitis associated with group C streptococcus pharyngitis. Clin Ophthalmol 2011, 5:1257-1259.

7. Thakker M, Perez V, Moulin A, et al: Multifocal Nodular Episcleritis and Scleritis with Undiagnosed Hodgkin's Lymphoma. Ophthalmol 2003, 110:1057-1060.

8. Chin K, Kempin S, Milman T, et al: Ocular manifestations of multiple myeloma: three cases and a review of the literature. Optometry 2011, 82:224-230.

9. Decaudin D, Dendale R, Lumbroso-Le Rouic L: Treatment of mucosaassociated lymphoid tissue-type ocular adnexal lymphoma. Anti-Cancer Drugs, 19:673-680

\section{doi:10.1186/1471-2334-13-149}

Cite this article as: Rospond-Kubiak et al:: Poststreptococcal syndrome mimicking conjunctival lymphoma. BMC Infectious Diseases 2013 13:149. 